\title{
NAS ONDAS DA INSUBORDINAÇÃO CRIATIVA: UMA INTERFACE ENTRE A EDUCAÇÃO ESTATÍSTICA E A BIBLIOTECONOMIA
}

\author{
ON THE WAVES OF CREATIVE INSUBORDINATION: AN INTERFACE \\ BETWEEN STATISTICAL EDUCATION AND LIBRARIANSHIP
}

\author{
Camila Rubira Silva \\ Universidade Federal do Rio Grande - FURG, Programa de Pós-Graduação em \\ Educação em Ciências/ camilarubira@hotmail.com \\ Suzi Samá \\ Universidade Federal do Rio Grande - FURG, Programa de Pós-Graduação em \\ Educação em Ciências / suzisama@furg.br
}

\begin{abstract}
Resumo
Nossa prática pedagógica e investigativa tem demostrado a necessidade de romper a fragmentação do conhecimento, em prol do diálogo e da interface entre as ciências. Como um caminho para esta ruptura, neste artigo, objetivamos refletir acerca de nosso ser/fazer docente na procura por pautar a proposta pedagógica da disciplina de Estatística Descritiva na interface desta com o Curso de Biblioteconomia. Instigadas por Beatriz D'Ambrosio e Celi Lopes, aventuramo-nos a mergulhar nas ondas da insubordinação criativa para a tomada de consciência deste ser/fazer docente. Para tanto, fundamentamo-nos na Teoria da Biologia do Conhecer, a qual destaca a importância da promoção de um espaço de convivência onde os saberes e contextos dos estudantes sejam legitimados. A partir das manifestações desses sujeitos sobre a rota pedagógica da disciplina, percebemos uma articulação entre os conceitos estatísticos e outros que integram as demais disciplinas do Curso. Esta proporcionou a criação de um ambiente de aprendizagem que possibilitou a compreensão da importância da Estatística no Curso, na futura profissão e na própria vida. Assim, convidamos outros docentes a navegar nas ondas da insubordinação criativa, a fim de promover a interface entre o conhecimento estatístico e o contexto acadêmico do estudante.
\end{abstract}

Palavras-chave: Ensino de Estatística, Biblioteconomia, Insubordinação Criativa.

\section{Abstract}

Our pedagogical and investigative practice has demonstrated the need to break the fragmentation of knowledge towards the dialogue and the interface between sciences. As a way for this rupture, in this paper, we aim to reflect about our being/making teacher in the search to guide the pedagogical proposal of the discipline of Descriptive Statistics in the interface of this with the Course of Librarianship. Encouraged by Beatriz D'Ambrosio and Celi Lopes, we venture into the waves of creative insubordination to become aware of this being/making teacher. Therefore, we are based on the Theory of Biology of Knowing, which highlights the importance of promoting a space of coexistence where students' knowledge and contexts are legitimized. From the manifestations of these subjects on the pedagogical proposal of the discipline, we perceive an articulation between the statistical concepts and 
others that integrate the other disciplines of the Course. This articulation provided the creation of a learning environment that promoted an understanding of the importance of Statistics in the Course of Librarianship, future profession and life itself. Thus, we invite other teachers to navigate the waves of creative insubordination in order to promote the interface between statistical knowledge and the academic context of the student.

Keywords: Statistics Education, Librarianship, Creative Insubordination.

\section{Iniciando a navegação na insubordinação criativa}

O cotidiano acadêmico, por vezes, leva-nos a reproduzir padrões e metodologias de ensino que, em vez de promover novos pensares, conduz à reprodução de uma prática docente que inibe a criatividade e a construção do conhecimento. Este cotidiano impregna, muitas vezes, a forma como a Estatística é trabalhada em sala de aula. Na contramão disto, nossa concepção do educar instigou-nos a desbravar outras rotas ao encontro de uma atitude insubordinada e de uma subversão responsável na nossa prática pedagógica.

De acordo com D’Ambrosio e Lopes (2015b), é preciso ter sensibilidade para entender contextos de alteridade, redimensionar velhas ideias, abrir-se ao novo, em prol de aprendizagens que contemplem a diversidade das áreas do conhecimento, como se estivéssemos em busca de outros mares. Nesta permanente procura, voltamos nosso olhar para o ensino de Estatística no curso de Biblioteconomia. A fim de promover o diálogo e a interface entre estas duas ciências, aceitamos o convite de D’Ambrosio e Lopes (2015b) para nos aventurarmos a navegar nas ondas que promovem as marés de saberes insubordinados, em um constante movimento de busca pelas teorias que sustentam nosso fazer docente e pela própria tomada de consciência do ser docente.

Neste movimento, encontramos sustentação no Modelo Pedagógico Relacional (BECKER, 2001; 2012) fundamentado em concepções epistemológicas construtivistas/interacionistas, como a Teoria da Biologia do Conhecer, proposta por Maturana e Varela (2005). Esta teoria tem profundas implicações para a educação, pois, segundo os autores, o viver não se separa do conhecer, o que nos leva a repensar os métodos pedagógicos tradicionais que, muitas vezes, são processos mecânicos estranhos ao viver.

Com este entendimento, planejamos uma proposta pedagógica para a disciplina de Estatística Descritiva contextualizada ao curso de Biblioteconomia, de modo a suscitar a construção dos conceitos estatísticos articulados a outros conhecimentos inerentes à atuação do Bacharel em Biblioteconomia. Assim, no presente artigo, objetivamos refletir acerca de nosso ser/fazer docente na procura pela insubordinação criativa na sala de aula da disciplina de Estatística no Curso de Biblioteconomia.

O texto está organizado em cinco seções. Inicialmente, apresentamos os percursos trilhados rumo ao encontro da insubordinação criativa, no qual abordamos aspectos sobre o ser e o fazer docente na Estatística. As próximas seções estão organizadas em três atos que representam, no nosso entendimento, atitudes de insubordinação criativa: 1) compreender o contexto do estudante; 2) privilegiar o estudante no centro do processo educativo e 3) incentivar o estudante a se manifestar em relação à rota pedagógica 
vivenciada. Por fim, tecemos algumas considerações em relação à criatividade no fazer pedagógico e investigativo.

\section{Nas ondas da insubordinação criativa: o ser e o fazer docente na rota da Estatística}

Ao longo do tempo, a Estatística vem se constituindo como uma ciência com emprego nas mais variadas áreas do conhecimento. Isto tem demandado a formação de diversos profissionais que necessitam lidar com grande quantidade de informações e tomar decisões frente a condições de incerteza. Diante disso, discussões sobre a Educação Estatística no Ensino Superior têm sido cada vez mais frequentes. Dentre estas, uma problemática recorrente é a apreensão dos estudantes em cursar uma disciplina de Estatística, a qual muitas vezes está associada a experiências anteriores - eventualmente traumáticas - de aprendizagem (VENDRAMINI; BRITO, 2001).

Por vezes, o ensino trabalhado de forma descontextualizada com a realidade dos estudantes, com foco na reprodução e memorização de conceitos estatísticos, pode desestimular o interesse nesta ciência. Esses sujeitos, por sua vez, passam a reduzir a Estatística à aplicação de fórmulas e resolução de cálculos, ignorando seu significado, bem como sua contribuição na sociedade e nas futuras profissões. Em contrapartida, acreditamos, assim como D'ambrosio e Lopes (2015b), que:

Um profissional da Educação que busque formar estudantes éticos e solidários não deve conceber o ensino como transmissão de conceitos já elaborados e construídos, não deve limitar sua prática docente apenas aos objetivos previamente determinados, sem considerar o contexto no qual seu aluno está inserido (D'AMBROSIO; LOPES, 2015b, p.4).

Como professores e pesquisadores do espaço educacional, precisamos reconfigurar nossa prática pedagógica e superar os paradigmas previamente determinados, em um movimento constante, semelhante ao fluir das ondas no mar. Para D'Ambrosio (2015):

[...] o conhecimento acadêmico a partir das disciplinas implica maneiras de ver o mundo, de interpretar fatos e fenômenos e de agir com métodos e resultados bem definidos e rigorosamente organizados para lidar com questões específicas. Metaforicamente, seriam como pássaros vivendo em uma gaiola. Alimentam-se do que está na gaiola, só veem e sentem o que as grades permitem (D’AMBROSIO, 2015, p.35).

Para promover a compreensão contextualizada dos conceitos estatísticos, precisamos ir para além das grades da gaiola. Como gaivotas que sobrevoam livres o mar, buscamos desenvolver práticas pedagógicas que nos conduzam a alçar voos insubordinados, mas sem perder de vista o rumo onde queremos chegar. Nesse processo de desacomodação, podemos encontrar outros lugares e navegadores, como Maturana (2010), segundo o qual, o conhecimento é ativo e construído nas interações com o mundo: "o mundo surge na dinâmica de nosso operar" (p. 31). Assim, "essa criação ocorre ao longo de nossas vidas, [...] em uma viagem comum, eu, nós e o mundo." (SAMÁ, 2012, p. 56). Com este entendimento, buscamos mergulhar nos contextos e lugares pelos quais os estudantes perpassam, legitimando seus saberes e promovendo a interação destes com a Estatística. 
Corroboramos com D'Ambrosio, Lopes e Corrêa (2016), para quem "os professores são a chave para criar um ambiente de sala de aula com ricas oportunidades para a aprendizagem" (p. 288). Também consideramos importante que neste ambiente se estabeleçam relações de afetividade, respeito e cumplicidade entre professores e estudantes. Conforme Maturana (2002), o conhecimento depende das interações recorrentes e do emocionar em que nos encontramos, pois é a emoção que nos conduz à ação. Assim, é fundamental refletir sobre o redimensionar de nosso fazer docente para que o processo de ensinar e de aprender Estatística ocorra em um espaço educacional em que estudantes e professores possam transformar-se na convivência.

De acordo com D'Ambrosio e Lopes (2015), nesta dinâmica de refletir acerca da própria prática, o professor passa a atuar dentro da perspectiva da insubordinação criativa. Ainda segundo as autoras, ao agir desta forma, o professor assume a imprevisibilidade no processo de construção do conhecimento e se dedica a ouvir os estudantes e colegas, em vez de considerar somente às diretrizes pré-estabelecidas pelas instituições e a replicar os métodos de ensino tradicionais, ancorados na mera transmissão de conceitos.

Quando movidos para melhorar a aprendizagem dos alunos e investir na melhoria das condições em que essa aprendizagem ocorre, os professores criam e colocam padrões de movimento e procedimentos que estão alinhados com a sua identidade profissional. Essas atitudes são de forma responsavelmente subversiva e resultam em atos de insubordinação criativa (D'AMBROSIO; LOPES; CORRÊA, 2016, p.288).

Neste movimento de construção da rota pedagógica da disciplina, questionamos os procedimentos metodológicos normalmente utilizados no ensino de Estatística. Segundo D’Ambrosio e Lopes (2015a), estes questionamentos permitem ao professor

[...] não apenas identificar as teorias que utiliza e as que está constantemente a elaborar, mas também tomar consciência de si próprio como profissional e como pessoa, nomeadamente em relação a suas capacidades, ao saber-fazer, aos valores e aos conhecimentos (D’AMBROSIO; LOPES, 2015a, p.7).

A partir deste questionamento e das teorias que subjazem este refletir acerca do ser e fazer docente, elaboramos a proposta pedagógica para o curso de Biblioteconomia, com vistas a atender as necessidades deste profissional no que tange ao tratamento da informação. Tal proposta foi delineada a partir das concepções do Modelo Pedagógico Relacional (BECKER, 2001; 2012) e da Teoria da Biologia do Conhecer (MATURANA; VARELA, 2005).

De acordo com Becker (2012), o Modelo Pedagógico Relacional presume um espaço de interação fluida entre o professor e os estudantes, no qual ambos aprendem e ensinam juntos. Com isso, as relações de sala de aula, de cristalizadas - com toda dose de monotonia que por vezes as caracteriza - podem passar a ser fluidas. O professor vai construindo sua docência diariamente, ao passo que os estudantes também o fazem com relação à sua "discência" (BECKER, 2012). Nesta perspectiva, a Teoria da Biologia do Conhecer, a qual parte do princípio de que o conhecimento é ativo e construído nas interações com o mundo, conduz-nos a romper com os métodos pedagógicos tradicionais. 
$\mathrm{Na}$ sequência, apresentamos os atos de insubordinação criativa, adotados com o intuito de legitimar o contexto no qual os estudantes estão imersos, de modo a articular os seus saberes com a Estatística. Para isto, inicialmente, mergulhamos nos documentos basilares do curso de Bacharelado em Biblioteconomia da Universidade Federal do Rio Grande - FURG, a fim de conhecer o perfil do estudante, bem como do futuro profissional.

Atitudes de insubordinação criativa: Ato 1 - Imersão inicial no contexto dos estudantes

O curso de Bacharelado em Biblioteconomia da FURG - incluído na grande área do conhecimento das Ciências Sociais Aplicadas, e na subárea Ciência da Informação - foi criado no ano de 1975. Ao longo do tempo, passou por diversas reformulações devido às transformações socioculturais e técnicas. A partir dessas, deu-se a construção do Projeto Político Pedagógico (PPP, 2015) vigente do curso, o qual propõe como meta

[...] formar bacharéis em Biblioteconomia, com uma visão crítica da sociedade, capacitando-os para a gestão da informação cultural, científica e técnica, registrada em múltiplos suportes, conscientes do compromisso ético da profissão com o primado do livre acesso aos registros do conhecimento (PPP, 2015, p.10).

Nesse sentido, o currículo do curso foi planejado e organizado de modo a promover a formação de bacharéis que atendam às competências e habilidades exigidas pelo perfil profissional que se pretende. Dentre as competências descritas no PPP (2015), destacamos: utilizar e disseminar informações contidas em fontes e recursos de informação, em quaisquer suportes; selecionar, registrar, armazenar, recuperar e difundir a informação gravada em qualquer meio, para os usuários de unidades, serviços e sistemas de informação; planejar e executar estudos e programas de formação de usuários da informação; realizar pesquisas e estudos sobre desenvolvimento e aplicação de metodologia de elaboração e utilização do conhecimento registrado.

A leitura reflexiva do PPP do curso de Bacharelado em Biblioteconomia nos possibilitou uma imersão inicial no contexto dos estudantes, de modo a compreender e legitimar seus saberes, articulando o ensino da Estatística aos diferentes campos de atuação dos futuros bacharéis. Sem nos limitar à descrição do perfil almejado, mergulhamos nas ondas da insubordinação criativa, ao planejar e executar a proposta pedagógica para a disciplina de Estatística no curso de Biblioteconomia, apresentada na próxima seção.

\section{Atitudes de insubordinação criativa: Ato 2 - Mergulhando na proposta pedagógica}

A proposta pedagógica foi desenvolvida com 35 estudantes regularmente matriculados na disciplina de Estatística Descritiva do curso de Bacharelado em Biblioteconomia. Esta é ofertada no terceiro semestre do curso, o que nos permite inferir que os estudantes já possuem uma base sobre o curso e algumas possíveis aplicações dos conceitos estatísticos. As atividades foram realizadas tanto no ambiente da sala de aula, quanto nos laboratórios do grupo de Pesquisa em Educação Estatística da Universidade. 
No intuito de legitimar o contexto e os saberes dos estudantes, tratamos de, por meio de quatro questionamentos, conhecer suas áreas de interesse, bem como suas crenças sobre o curso e sobre o ensino de Estatística. Para D’Ambrosio e Lopes (2015a) um profissional da Educação que busque formar estudantes éticos e solidários precisa considerar o contexto no qual o estudante está inserido, pois a "[...] atuação docente dependerá de sua sensibilidade para perceber e respeitar o processo de desenvolvimento intelectual e emocional dos alunos" (p.4).

Nesse sentido, fizemos os seguintes questionamentos: "Minha carreira em Biblioteconomia me faz pensar em ...?"; "Estatística me faz pensar em ...? "; "Quais as áreas de que você mais gosta na Biblioteconomia? "; "Qual a aplicação da Estatística na sua área de preferência?". As respostas dos estudantes a estes questionamentos foram sistematizadas em nuvens de palavras, as quais possibilitam apresentar resultados de dados qualitativos. O tamanho com que as palavras são graficamente distribuídas na nuvem expressam de forma compreensível e visualmente clara a frequência com que estas foram mencionadas no corpus de análise (CAMARGO; JUSTO, 2013).

As palavras evocadas pelos estudantes a partir do primeiro questionamento (Figura 1) integram o conjunto de memórias destes. Para Tardif (2000), essas memórias decorrem das experiências formadoras vivenciadas na família e na instituição de ensino.

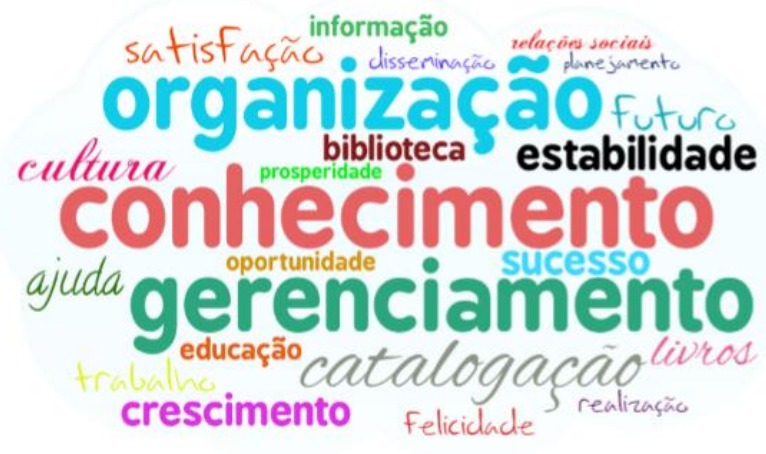

Figura 1: Nuvem "Biblioteconomia me faz pensar em..."

O segundo questionamento possibilitou perceber que o ensino da Estatística ainda é realizado de forma descontextualizada com a realidade dos estudantes. Conforme Figura 2, podemos observar que o foco ainda está na resolução de cálculos e na aplicação de fórmulas, o que acaba desencadeando nos estudantes marcadores associados à aprendizagem dos conceitos estatísticos como um "problema", "dificuldade" e que precisa de "dedicação", "superação".

Estudos de Vendramini e Brito (2001) apontam que muitos estudantes do Ensino Superior ficam apreensivos em cursar uma disciplina obrigatória de Estatística, ingressando com atitudes negativas em relação a esta. No entanto, ao vivenciarem experiências agradáveis em sala de aula com propostas articuladas à sua área de atuação, as autoras destacam que os estudantes passam a compreender melhor o significado e a importância da Estatística para o desempenho de suas futuras profissões. 


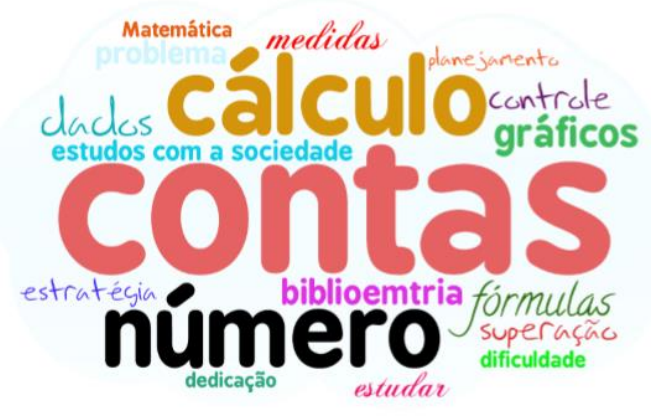

Figura 2: Nuvem "Estatística me faz pensar em..."

Os estudantes também foram questionados sobre a área de preferência na Biblioteconomia (Figura 3); e a aplicação da Estatística em tal área (Figura 4). Dentre as áreas destacadas estão "biblioteca escolar"; "pesquisa"; "biblioteca universitária". A escolha por estas áreas pode estar relacionada ao contexto em que os estudantes estão inseridos, uma vez que alguns atuam como bolsistas de pesquisa e extensão nos ambientes destacados. Dessa forma, a aplicabilidade da Estatística em tais áreas foi vislumbrada através do estudo do "uso e usuário", no "levantar dados", na "administração de livros" (Figura 4).

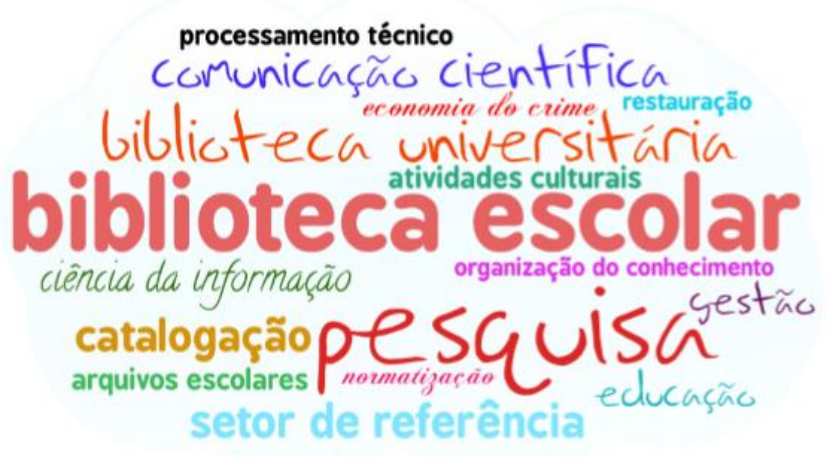

Figura 3: Quais áreas de que você mais gosta?

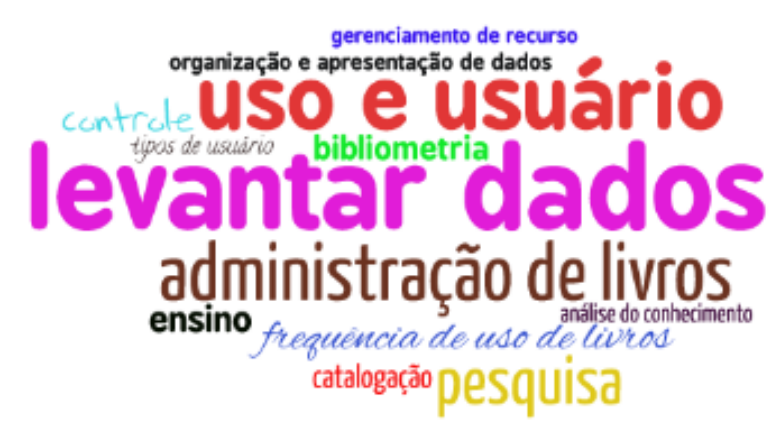

Figura 4: Qual aplicação da Estatística na sua área de preferência?

Com base nas respostas aos questionamentos, propomo-nos a desmitificar a concepção de que a Estatística se reduz à aplicação de fórmulas e resolução de cálculos. Entendemos que esta visão decorre dos métodos de ensino ainda vigentes, tanto na escola quanto no meio acadêmico, no que se refere a disciplinas como a Matemática e a Estatística. Assim, buscamos aproximar o ensino da Estatística ao contexto dos estudantes, no intuito de revelar a potencialidade desta ciência na futura profissão e instigar seu estudo. Tal atitude vai ao encontro da insubordinação criativa, a qual, segundo D'Ambrosio e Lopes (2014), consiste na tomada de

[...] consciência sobre quando, como e por que agir contra procedimentos ou diretrizes estabelecidas. Ser subversivamente responsável requer assumir-se como ser inconcluso, que torna a curiosidade como alicerce da produção de conhecimento e faz de seu inacabamento um permanente movimento de busca (D’AMBROSIO; LOPES, 2014, p.29). 
Com esse entendimento, propusemos uma pesquisa bibliométrica, a fim de aproximar a Estatística do contexto do curso. Esta é definida por Araújo (2006) como uma "[...] técnica quantitativa e estatística de medição dos índices de produção e disseminação do conhecimento científico" (p.12). Vendramini e Brito (2001) também defendem o ensino da Estatística por meio da pesquisa, esclarecendo que a abordagem desta proposta desafia os estudantes a utilizarem as técnicas estatísticas de análise de dados no seu campo de atuação.

No desenvolvimento da pesquisa bibliométrica, orientamos os estudantes a se agruparem em equipes de trabalho. Para Maturana (2001), como seres sociais que somos, constituímos nosso espaço nas interações com o outro e com o meio, compreendendo a importância de nossas ações, construindo os mundos em que vivemos. Assim, consideramos que, através do trabalho coletivo, do compartilhamento de conhecimentos e da cooperação entre os colegas, a proposta possa ser potencializada, a fim de contribuir tanto na formação profissional, quanto pessoal dos estudantes.

A partir da formação dos grupos, estes foram orientados a fazer um levantamento de produções científicas (artigos, dissertações, teses e livros). Neste processo de pesquisa, os estudantes utilizaram as palavras-chave Educação Estatística e Ensino de Probabilidade, filtrando as produções dos últimos cinco anos, publicadas em bases de dados digitais, como periódicos, anais de eventos, Biblioteca Digital de Teses e Dissertações (BDTD) e a biblioteca institucional da Universidade. Rodrigues e Guimarães (2003) destacam que a pesquisa é um importante componente no processo de aprendizagem do futuro Bacharel em Biblioteconomia:

Ao recuperar a relação entre ensino e pesquisa, os educadores da área assumem que pelo ensino também se faz produção do conhecimento, incluindo, no cerne desse processo, a produção da consciência das novas gerações, fazendo-os sujeitos da própria história, capazes de enfrentar com independência e cidadania os desafios que se avizinham em um mundo tecnológico e globalizado (RODRIGUES; GUIMARÃES, 2003, p.160).

A partir desse levantamento, os estudantes analisaram o título, as palavras-chave e o resumo de cada produção, organizando os dados em uma planilha eletrônica de acordo com as seguintes informações: ano de publicação; instituição de ensino promotora da pesquisa; foco do trabalho (formação de professores, estratégia pedagógica, conceitos específicos, etc.); nível de ensino (Fundamental, Médio, Superior, Jovens e Adultos); estado ou país; dentre outras informações que julgassem importantes. Posteriormente, tais dados foram sistematizados e resumidos com base nos conceitos estatísticos estudados em sala de aula (como tabelas, gráficos e medidas estatísticas).

Para Silva e Schimiguel (2014), apesar da planilha eletrônica ter fácil acesso entre os estudantes, "[...] poucos sabem utilizar eficientemente como uma ferramenta auxiliar no tratamento estatístico de dados e construção de gráficos estatísticos" (p.67). Os autores consideram que, ao proporcionarmos propostas pedagógicas com o auxílio de recursos tecnológicos, possibilitamos, além da aproximação dos ambientes educacional e profissional, aulas mais participativas e dinâmicas, sem prescindir do conhecimento relevante, que passa a ser construído pelos estudantes (SILVA; SCHIMIGUEL, 2014). 
Nesta etapa da pesquisa, auxiliamos os estudantes, por meio do esclarecimento de questionamentos e dúvidas sobre a construção das formas de organização e apresentação de dados. Vendramini e Brito (2001) consideram que o ensino da Estatística em todas as áreas do conhecimento nas quais ela está inserida seja orientado pela "[...] formação de profissionais competentes que saibam usar cuidadosa e adequadamente as técnicas estatísticas, com atitudes positivas em relação à (sic) essa disciplina, ao seu uso e à sua aplicação prática" (p.67-68).

Com os dados organizados e analisados, os estudantes construíram infográficos (Figura 5) para apresentação das pesquisas bibliométricas aos colegas da turma. Estes foram escolhidos por considerarmos que consistem em um modo de apresentar a informação por meio de texto verbal (escrita) e não verbal (gráficos estatísticos, ilustrações, mapas, entre outras imagens), no intuito de promover uma leitura dinâmica e atrativa ao leitor.

Para Kanno (2013), o fato de esta forma de apresentação ser predominantemente visual e utilizar uma linguagem verbal direta permite uma leitura mais rápida e compreensão mais imediata das informações por parte dos leitores. Na elaboração dos infográficos, os estudantes puderam sintetizar e organizar, de forma criativa, as informações da pesquisa.

Assim, ao planejar e executar esta proposta pedagógica, construímos uma interface entre a Educação Estatística e a Biblioteconomia. Isto contribui para o desenvolvimento de uma das especialidades atribuídas ao curso, a saber, a bibliometria, de forma articulada aos conhecimentos estatísticos.
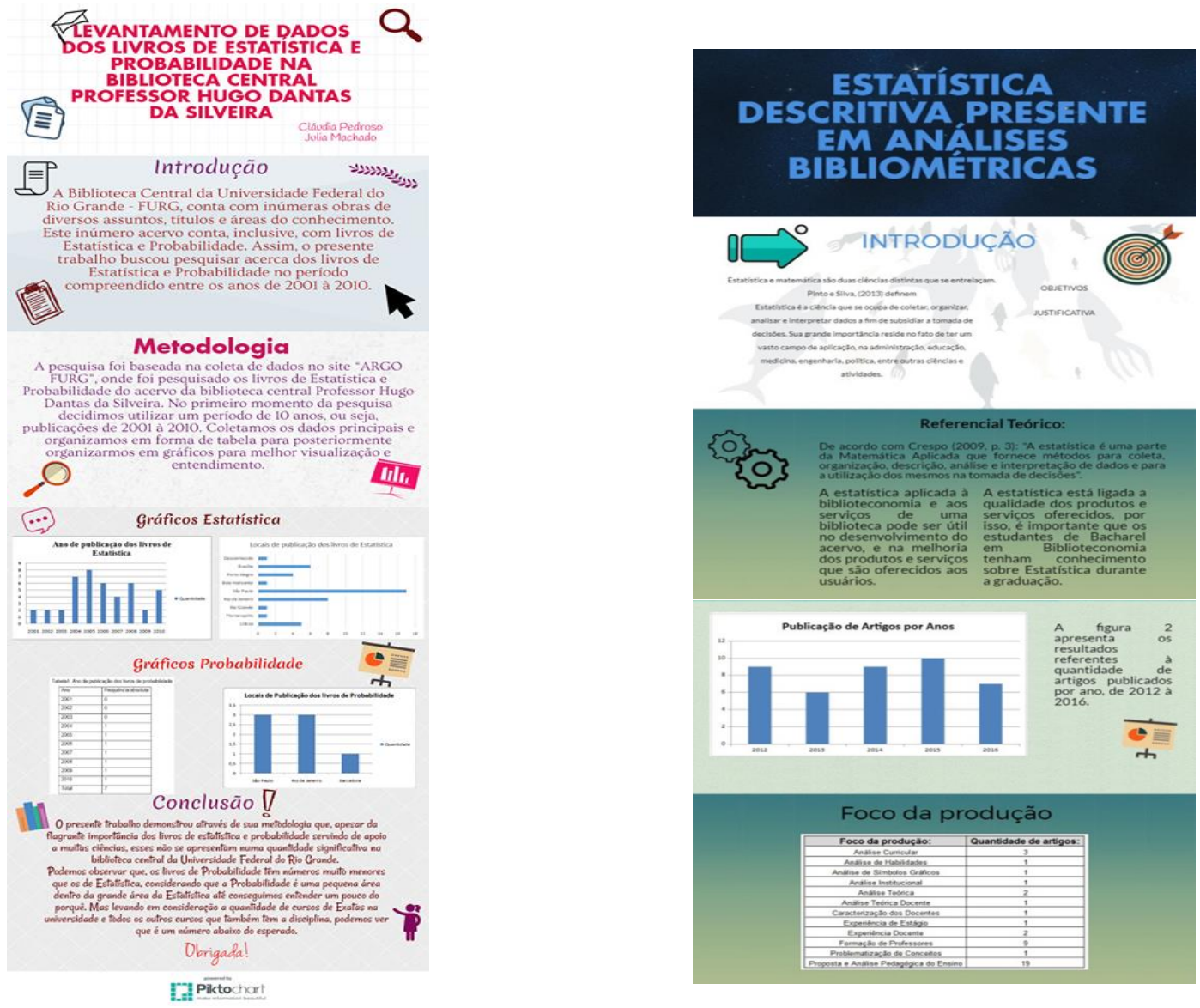

Figura 5: Recorte dos infográficos construídos pelos estudantes 
Na próxima seção, apresentamos as manifestações dos estudantes sobre a proposta pedagógica, a fim de verificar em que medida esta promoveu a interface da Estatística com o Curso de Biblioteconomia.

\section{Atitudes de insubordinação criativa: Ato 3 - Legitimando o outro}

Com base na Teoria da Biologia do Conhecer, que destaca a importância da legitimação do outro, iniciamos a disciplina por meio do diálogo com os estudantes, a fim de ouvir os seus anseios e saberes. Por coerência, a finalização desta não poderia ser de outra forma. Assim sendo, solicitamos, ao término da disciplina, que os estudantes se manifestassem sobre a proposta pedagógica, por meio do questionamento: "O ensino da Estatística contextualizado ao curso de Biblioteconomia promoveu maior interesse pela disciplina de Estatística Descritiva? Explique". Obtivemos 29 respostas dissertativas. Com estas, realizamos uma análise interpretativa, discutindo os trechos das escritas à luz da Teoria da Biologia Conhecer, proposta por Maturana e Varela (2005).

A escolha pela abordagem qualitativa neste estudo justifica-se por esta possibilitar responder a questões muito particulares sobre o fenômeno investigado, as quais não podem ser quantificáveis. Segundo Minayo (2001) a pesquisa qualitativa trabalha com "[...] o universo dos significados, motivos, aspirações, crenças, valores e atitudes, o que corresponde a um espaço mais profundo das relações, dos processos e dos fenômenos" (p.14). Ao longo da análise das manifestações dos estudantes buscamos compreender parte da realidade vivida pelo estudante durante a disciplina e de que forma estes perceberam a rota pedagógica e a sua contribuição, ou não, na sua formação, enquanto futuros bacharéis em biblioteconomia. Assim, classificamos as respostas dos estudantes em duas categorias: "Canto da seria" e "Desvio de rota". A seguir apresentamos cada uma destas categorias.

A primeira categoria intitulada "Canto da sereia", que retrata a sedução emocional possibilitada pela proposta pedagógica, é composta por $83 \%$ dos estudantes. Esses consideraram ter maior interesse na disciplina a partir da contextualização do ensino da Estatística com o curso. Nos excertos a seguir, podemos ver a compreensão dos estudantes sobre a importância desta ciência para a formação profissional:

Sim, pois auxiliou para uma maior compreensão da importância da mesma para o bibliotecário. (Estudante 1)

Acredito que sim, pois a pesquisa em bases de dados, a construção de gráficos faz parte da profissão do bibliotecário pesquisador, ou seja, a busca por conhecimento requer a Estatística. (Estudante 2)

Nas concepções de Maturana (1997), "[...] todas as ações humanas, independentemente do espaço operacional em que se dão, se fundam no emocional porque ocorrem no espaço de ações especificado por uma emoção" (p.175). Dessa forma, ao buscarmos desenvolver nossa prática pedagógica no compromisso de instigar os estudantes, a partir da contextualização do ensino da Estatística ao curso de Biblioteconomia, passamos a construir um sistema de convivência, constituído na emoção do amor, legitimando e aceitando os estudantes. 
Os sistemas sociais são sistemas de convivência originados a partir do amor, formando um espaço de ações de aceitação do outro na convivência. Nos sistemas de trabalho, a emoção de origem é a do compromisso, na aceitação do outro para realização de uma tarefa. (MATURANA, 1997, p.176).

Contrário aos sistemas de convivência pautados no amor, há os hierárquicos e de poder. Nesses, o ensino é firmado na negação do outro, os conceitos são trabalhados com propostas pedagógicas desvinculadas da realidade dos estudantes, apenas com a finalidade de cumprir a ementa sugerida nas disciplinas: "Já nos sistemas hierárquicos e de poder, predominam as emoções que definem um espaço de ações de autonegação e negação do outro na aceitação da submissão própria ou da do outro, numa dinâmica de ordem e obediência" (MATURANA, 1997, p.176).

No excerto dos Estudante 3 e 11, percebemos a desmitificação das percepções do ensino da Estatística geradas em espaços hierárquicos e de poder.

Com certeza, desconstruí a relação da Estatística a cálculos em níveis difíceis de serem compreendidos. As análises de dados com uma compreensão melhor das variáveis e de como organizá-los e interpretá-los torna-se imprescindível para o curso de Biblioteconomia (Estudante 3).

Na minha percepção quando entramos no curso de Biblioteconomia e nos deparamos com algumas disciplinas como, por exemplo, estatística não temos ideia de qual será a finalidade dela com a nossa formação já que são linhas opostas uma é voltada para sociais aplicada e outra para área das exatas e muitos assim como eu não se familiariza com essa área do conhecimento o que já de ante mão faz com que tenhamos uma certa restrição, na minha opinião isso se deve pela maneira que temos contato lá nos anos iniciais de educação já que a mesma é associada a matemática, na qual somos obrigados a sempre decorar fórmulas e fazer cálculos desgastantes sem trazer para a nossa vivencia do cotidiano [...]E para finalizar eu consegui obter êxito nesse semestre em estatística inclusive tirei um 10 no primeiro bimestre o que me causou grande espanto, mas o mais gratificante não é a nota em si e sim saber que eu tirei essa nota sabendo que eu aprendi realmente o conteúdo e que sei que realmente irei usar estatística e muito na minha vida como futura bibliotecária, e isso se deve porque pude ver que a disciplina não é somente fórmulas e cálculos como nós temos em nosso pensamento e acredito que seja pela proposta de trabalho que as professoras propuseram para nós. (Estudante 11).

A manifestação da estudante com relação à proposta pedagógica reflete a concepção de Maturana (2001) que orientou o planejamento da disciplina: educar é conviver em um espaço de aceitação recíproca, onde haja respeito pelo outro. Tal reflexão vai ao encontro do que é defendido por D’Ambrosio, Lopes e Corrêa (2016), para quem: 
Os professores são a chave para criar um ambiente de sala de aula com ricas oportunidades para a aprendizagem. É sua a responsabilidade de propor e organizar tarefas e coordenar as atividades de aprendizagem de desenvolvimento para seus alunos. (D'AMBROSIO; LOPES; CORRÊA, 2016, p.288).

$\mathrm{Na}$ proposta desenvolvida na disciplina de Estatística Descritiva, os estudantes perceberam a articulação dos conhecimentos aprendidos com outras disciplinas do curso, como podemos observar nas seguintes manifestações:

[...] muitos dos conhecimentos obtidos foram utilizados em outras disciplinas. (Estudante 4)

[...] o mais relevante para mim foi o trabalho proposto no qual tivemos que escolher uma base de dados, depois coletar determinadas informações para serem expostos em um quadro, analisar e escrever sobre todo o tema do trabalho porque é isso que aprendemos durante a graduação de Biblioteconomia. (Estudante 11)

[...] com a Estatística aprendi a construir gráficos, tabelas e a interpretá-las em meus trabalhos acadêmicos. (Estudante 5)

A partir destas manifestações podemos constatar a importância do professor de Estatística adotar metodologias de ensino que considerem o contexto em que os estudantes estão inseridos. A articulação dos conceitos estatísticos com outros conhecimentos da área do curso dos estudantes potencializa a aprendizagem.

A segunda categoria intitulada "Desvio de rota" emerge nos discursos dos estudantes que responderam negativamente ao questionamento: "O ensino da Estatística contextualizado ao curso de Biblioteconomia promoveu maior interesse pela disciplina de Estatística Descritiva?". Apesar dos esforços em organizar uma proposta pedagógica que possibilitasse a construção dos conceitos estatísticos articulados com o Curso de Biblioteconomia, para $14 \%$ dos estudantes, esta não repercutiu positivamente. Nos excertos de alguns estudantes, ainda verificamos a associação da Estatística a fórmulas e cálculos, bem como à exigência de autossuperação:

Não, é muito confuso as fórmulas. (Estudante 6)

Particularmente não. Tenho dificuldade (enorme) com números, cálculos, etc. Estou conseguindo me superar, isso pra mim já é o suficiente no momento. (Estudante 15)

Com certeza não. A maioria se dedica pra passar porque tranca outras disciplinas (Estudante 8).

Os efeitos de uma aula, na qual o ensino da Estatística seja descontextualizado da realidade dos estudantes, com foco na memorização de fórmulas e resolução de cálculos, pode gerar nos estudantes crenças e atitudes negativas quanto ao seu ensino e aprendizagem difíceis de serem superadas, como podemos observar nos referidos excertos. Maturana (2002) destaca que a educação se configura em um processo contínuo que se estende por toda vida, sendo conservado por gerações, o que "(...) não significa, é claro, que o mundo do educar não mude, mas sim que a educação, como sistema de 
formação da criança e do adulto, tem efeitos de longa duração que não mudam facilmente" (p.29).

A vida caracteriza-se como um permanente processo de conhecimento. Este processo é, no entanto, gradativo e subjetivo. Assim, no que diz respeito ao âmbito educacional, em particular neste estudo, entendemos que nem todos os estudantes sentem-se seduzidos por tal proposta pedagógica. Ainda segundo Maturana (2002) 0 discurso "que não seduz emocionalmente não muda o espaço do outro" (p.124).

\section{Breve parada na navegação pela insubordinação criativa}

Ao longo deste texto navegamos pelas ondas da insubordinação criativa na busca por legitimar o espaço e o contexto vivido pelos futuros bacharéis em Biblioteconomia em formação. Nesta busca, construímos uma rota pedagógica que buscou promover a interface entre a Estatística e a Biblioteconomia. Tal construção foi sendo delineada a partir do diálogo estabelecido por meio dos textos de Beatriz D’Ambrosio e Celi Lopes, pois pelo texto adquirimos experiências novas e ao final deste, já não somos mais os mesmos.

As reflexões aqui tecidas se estabeleceram em um movimento constante, em um processo que inicia na busca pelo ser e fazer docente na disciplina de Estatística e culmina em um produto provisório, que recomeça nas interrogações encontradas ao longo da pesquisa. Conhecer o outro, neste caso, os futuros bacharéis em biblioteconomia, por meio de suas manifestações consiste em reconhecê-los como legítimo outro com base em suas vivências.

A partir das manifestações dos estudantes podemos constatar, na maioria, uma desconstrução do ensino de conceitos estatísticos resumidos a aplicação de fórmulas e resolução de exercícios, demostrando uma melhor compreensão dos estudantes a respeito da relevância da Estatística a sua formação e na própria vida.

A legitimação dos contextos dos estudantes e das manifestações destes em relação às áreas de interesse e ao ensino de Estatística contribuiu para a ruptura da fragmentação entre a Estatística e Biblioteconomia. Importante destacar que não é possível garantir que a proposta pedagógica por mais insubordinada que seja irá sensibilizar todos os estudantes a ponto de promover a almejada interface entre a Estatística e a Biblioteconomia. Tal constatação demonstra que o fazer docente está em constante construção e o ser docente como essencialmente inconcluso.

Diante de tais considerações, convidamos outros docentes a mergulharem nas ondas da insubordinação criativa na busca, tanto de teorias, como a Teoria da Biologia do Conhecer, que possam sustentar seu fazer docente, como também a própria tomada de consciência do ser docente.

\section{Referências}

ARAÚJO, Carlos Alberto. Bibliometria: evolução história e questões atuais. Em Questão, Porto Alegre (RS), v.12, n.1, p.11-32, jan./jun. 2006. 
BECKER, F. Modelos pedagógicos e modelos epistemológicos. In: . Educação e construção do conhecimento. Porto Alegre: Artmed. 2001, p. 15-32.

BECKER, F. A Epistemologia do Professor: o cotidiano da escola. 13 ed. Petrópolis, RJ: Vozes, 2012.

CAMARGO, B. V.; JUSTO, A. M. IRAMUTEQ: um software gratuito para análise de dados textuais. Temas psicol., Ribeirão Preto, v. 21, n. 2, p. 513-518, dez. 2013. Disponível em <http://dx.doi.org/10.9788/TP2013.2-16>. Acesso em: jun. 2017.

D'AMBROSIO, U. Insubordinação Criativa na Educação e na Pesquisa: das disciplinas à transdisciplinaridade. In: D'AMBROSIO, B.; LOPES, C. (Org.) Vertentes da Subversão na produção Científica em Educação Matemática. Insubordinação Criativa. Campinas, SP: Mercado de Letras, 2015, p.17-42.

D'AMBROSIO, B.; LOPES, C. Insubordinação Criativa: um convite à reinvenção do educador matemático. Bolema, Rio Claro (SP), v.29, n.51, p.1-17, abr. 2015a.

D'AMBROSIO, B.; LOPES, C. (Org.) Vertentes da Subversão na produção Científica em Educação Matemática. Insubordinação Criativa. Campinas, SP: Mercado de Letras, 2015b.

D'AMBROSIO, B.; LOPES, C. Trajetórias de Educadoras Matemáticas. Campinas, SP: Mercado de Letras, 2014.

D'AMBROSIO, B.; LOPES, C. CORRÊA, S. A. A Insubordinação Criativa em Educação Matemática Promove a Ética e a Solidariedade. Zetetiké, Campinas (SP), v.24, n.3, p.287300, set./dez.2016.

KANNO, M. Infografe: Como e porque usar infográficos para criar visualizações e comunicar de forma imediata e eficiente. São Paulo: Edição eletrônica, 2013.

MATURANA, H. A ontologia da realidade. Belo Horizonte: Editora: UFMG, 1997.

Cognição, ciência e vida cotidiana. Belo Horizonte: Editora: UFMG, 2001, $203 p$.

UFMG, 2002, 98p.

Emoções e linguagem na educação e na política. Belo Horizonte: Editora:

El Sentido de lo Humano. Buenos Aires: Granica; Juan Carlos Sáez, 2010.

MATURANA, H. R.; VARELA, F. A árvore do conhecimento: as bases biológicas da compreensão humana. 5ª ed. São Paulo: Palas Athena, 2005.

MINAYO, M. C. S. Pesquisa social: teoria, método e criatividade. Petrópolis - RJ: Vozes, 2001. $80 \mathrm{p}$. 
Projeto Político Pedagógico do curso de Biblioteconomia da Universidade Federal do Rio Grande - FURG. Rio Grande, 2015.

RODRIGUES, M.; GUIMARÃES, J. A dimensão pedagógica da pesquisa nos cursos de biblioteconomia do mercosul: reflexões sobre uma trajetória de harmonização curricular. Transinformação, v.15, n.2, p.149-163, 2003. Disponível em: <http://www.brapci.ufpr.br/brapci/v/a/366>. Acesso em: abril, 2017.

SAMÁ, S. P. Carta de navegação: abordagem multimétodos na construção de um instrumento para compreender o operar da modalidade a distância". Tese (Doutorado). Rio Grande: FURG, 2012.

SILVA, J. F. SCHIMIGUEL, J. Uso das tecnologias de informação e comunicação como contribuição à Educação Estatística no Ensino Superior. REnCiMa, Edição Especial: IV Encontro de Produção Discente, v.6, n.1, p.64-74, 2015.

TARDIF, M.; RAYMOND, D. Saberes, tempo e aprendizagem do trabalho no magistério. Educ.Soc. v.21, n.73, p.209-244, 2000. Disponível em: < http://www.scielo.br/pdf/es/v21n73/4214.pdf>. Acesso em: maio 2017.

VENDRAMINI, M.; BRITO, M. Relações entre atitude, conceito e utilidade da Estatística. Psicologia Escolar e Educacional. v.5 n.1, p.59-73, 2001.

Submissão: 10/08/2017

Aceite: 05/11/2017 